\title{
Electrical Receptacles - Overheating, Arcing, and Melting
}

\author{
Matthew Benfer and Daniel Gottuk \\ Hughes Associates Inc \\ 3610 Commerce Drive, Suite 817 \\ Baltimore, MD 21227
}

\begin{abstract}
This study was designed to experimentally characterize factors that can cause electrical failures (i.e., overheating connections), to assess the damage and potential forensic signatures of these failures, and to characterize the similarities and differences between arcing and melting in receptacle components and wiring. Laboratory testing evaluated the impact of a wide range of variables on the formation of overheating connections in residential duplex receptacles including screw terminal torque, wiring method (back-wired, or side-wired), and primary receptacle materials. A total of 408 trials of receptacles with various terminal connections were tested in the laboratory setting; receptacles were powered for up to 16 months. A small portion of receptacles with loose connections overheated to the point of failure of the receptacle; some including flaming events. Failure events occurred between 5 and 365 days after tests were started. Four hundred and sixty eight (468) receptacles were placed in compartment fire tests and furnace fire tests. These tests were designed to evaluate the persistence after fire exposure of overheating/arcing evidence from failure events (i.e., from potential fire cause events). The fire exposure tests also served to analyze the characteristic traits of arcing and melting damage. The results indicated that only very loose connections (less than $0.339 \mathrm{~N}-\mathrm{m}$ [3 in-lb]) at moderately high currents (9A or higher) tend to form significant overheating connections and receptacle failures, irrespective of other variables such as receptacle materials and installation. Characteristic indicators of overheating and glowing terminal connections were identified and were found to persist after fire exposure.
\end{abstract}

KEYWORDS: Forensics, fire investigation, receptacles, arcing, ignition.

\section{INTRODUCTION}

Although electrical faults are attributed to causing a large proportion of structural fires [1], there is still much uncertainty in clearly identifying post-fire forensic indicators of electrical fires. Generally, the statistics reported do not include the physical mechanism that led to the device malfunction/cause of a fire [1]. In addition, limited studies have evaluated the mechanisms leading to electrical fires and the potential for the initiating event to be a competent ignition source of other combustibles. Therefore, there is a need to explore these mechanisms and to establish forensic methods and indicators that will improve the ability to make cause determinations in electrical fires.

A prominent cause of electrical fires in receptacles is overheating at loose terminal connections. In all electrical circuits, current flow through conductors and connections create heat due to the electrical resistance. This is called ohmic heating. Even when operating at or over a conductor's rated ampacity, most of the heat generated is dissipated into the environment. When two electrical conductors make firm contact over a large surface area relative to the cross-sectional area of the conductors, a good connection is formed and ohmic heating at the connection is minimal. However, loose terminal connections typically result in reduced contact area between conductors. The passage of current through a loose copper connection (i.e., a reduced contact area) heats the contact area, causing the formation of oxide layers on the copper. The rate of oxide production is based on the density and type of oxide film and the temperature at which the oxide is formed [2]. Below approximately $1100^{\circ} \mathrm{C}$, copper oxide $(\mathrm{CuO})$ is formed and above this temperature, cuprous oxide $\left(\mathrm{Cu}_{2} \mathrm{O}\right)$ is formed. $\mathrm{CuO}$ is generally dark black in appearance, while $\mathrm{Cu}_{2} \mathrm{O}$ is a reddish color; both are semi-conductive materials. Because the copper oxides are semi-conductive materials, as the layer of oxidation builds between the contacts, a high-resistance connection forms. This high-resistance connection will heat up and exacerbate the formation of additional copper oxides.

Eventually, high-resistance connections can heat to the point of glowing, which can persist for minutes, hours, or days [3]. Overheating and glowing connections have been studied in copper wiring by a number of authors [3-9]. These studies used different methods to initiate a glowing connection and examined a wide range of currents (0.5-20 amps) and voltages (120-220 volts AC). In general, these studies were 
either conducted on short time scales (i.e., hours and days) or tested configurations that were not realistic representations of receptacle connections (i.e., two vibrating wires). Despite the number of studies in which glowing connections have been formed, the conditions for overheating connections that actually lead to flaming ignition are still lacking. In addition, the forensic evidence resulting from overheated connections is not well documented. Korinek et al. recently studied overheating in poor connections between copper wiring and nickel plated steel receptacle screws [7]. To produce glowing on short time scales, the connections between the wire and screw were made by laying the wire on the screw head rather than having the wire wrapped around the screw. These researchers found that glowing connections (comprised of copper, iron, and oxygen) would melt and re-solidify in layers forming a "nugget." The glowing area was observed to move along the interface between the wire and screw head; necking of the glowing conductor was also observed [7]. These researchers observed a "burn-open" of the wire (i.e., severed conductor), which stopped current flow, at the point of the glowing liquid copper oxides. A chapter on electrical fires from a fire investigation book has also noted that "many overheating connections burn themselves out and break the electrical circuit without causing the fire [10]." Though it is unclear whether this particular statement was substantiated by personal experience or experimental research, it mirrors the behavior observed by Korinek et al.

Some attempt has been made to identify differences between receptacles that exhibited overheating connections (i.e., potential ignition sources) and those that were damaged due to fire [11]. It was noted that damage from a fire decreases from the exposed face to the back of the receptacle and is not concentrated near terminal screw connections, while damage from an overheated connection exhibits a radial pattern of damage spreading from the overheated terminal [11]. Other researchers observed that pitting and other evidence that may point to electrical activity at a connection were produced in fires with non-energized receptacles [12]. Though there has been some study related to forensic signatures of overheating connections, there is still a large gap in the body of knowledge on this subject.

Often after a fire has occurred, many of the electrical components and devices are damaged, charred, or melted. It is generally difficult to determine whether a damaged electrical component was a cause of the fire or damaged as a result of a fire, especially if the damage is extensive. At the time of this report, there are proposals for the 2014 edition of NFPA 921, Guide for Fire and Explosion Investigations [13], which are aimed at improving the discussion of arc beads and melting of conductors by fire [14]. This is a significant step in providing fire investigators with state of the art research regarding this topic. However, the majority of the proposed language is focused on arcing and melting of copper conductors. Also, the characteristic traits presented for arcing and melting are mostly qualitative and some would be significantly improved with quantitative criteria.

\section{EXPERIMENTAL APPROACH}

The two global objectives of this work were to improve the forensic examination of electrical receptacles and to better understand the potential causes of electrical fires in receptacles. There were two primary areas of interest explored: the development of overheating terminal connections in receptacles, and forensic examination of receptacles damaged from overheating and fire exposure. Laboratory testing of receptacle connections and fire exposures to exemplar and overheated connections were used to accomplish the objectives of this research. The two types of fire exposures were single-room compartment fires and an intermediate scale furnace. Large quantities of receptacles were evaluated in this test program in order to provide adequate data for evaluating the effects of multiple variables as well as providing a substantial dataset to establish a quantitative understanding of the accuracy and reliability of forensic indicators.

\section{Laboratory Testing}

The laboratory testing was designed to expose various receptacle configurations to operating conditions resembling a wide range of residential and commercial applications [15]. The testing allowed for overheating connections to develop naturally over extended periods of time such that the failures encountered would be representative of what could happen in real scenarios. Receptacles were energized for periods of up to 511 days; all receptacles were tested for a minimum of 204 days. The receptacles were mounted directly to steel test racks, which served as the common ground. Each rack consisted of 52 to 78 receptacles, and receptacles on each rack were wired using a feed through method such that the applied current was passed through both the hot and neutral terminals of every receptacle. This method was 
convenient from the standpoint that an electrical load could be applied to large numbers of receptacles using a single load bank. The wiring used to connect the receptacles was 14 AWG non-metallic (NM) sheathed cable. Receptacles were connected to the wiring for adjacent receptacles using wire nuts. Each test rack was connected to a separate $20 \mathrm{~A}$ circuit breaker. The electrical load for the test racks was provided by tungsten-filament light bulbs arranged in a load bank capable of providing a maximum current draw of 20A. A separate load bank was used for each test rack. During the majority of the tests, the receptacles were energized continuously with the exception of 1 hour each weekday where the circuits were deenergized. Some receptacles were subjected to vibration for 1 hour each weekday. Vibration of one test rack, was accomplished using a vibration motor (Precision Microdrives Model 345-800) located approximately at the center of the bottom row of the test rack. For the majority of the test, the power supplied to the motor was $17 \mathrm{VDC}$, which produced a vibration amplitude of approximately $6.5 \mathrm{G} \mathrm{at} 40 \mathrm{~Hz}$ based on the motor's output curve. Video surveillance systems were used to record failure events.

\section{Fire Exposure Testing}

The exposure of receptacles to compartment fires and an intermediate scale furnace had two purposes. Both the compartment and furnace exposures were used to assess the impact of certain variables relative to thermal damage and fire-induced electrical arcing in receptacles. The furnace fire exposures were also used to determine whether evidence of overheating and arcing related to ignition events (determined in laboratory tests) would persist after different levels of fire exposure. Compared to the compartment fires, the intermediate scale furnace allowed for controlled temperature exposures to the receptacles, representative of flashed over fire conditions and above those reached in the compartment fires. The compartment fires consisted of a single room furnished with upholstered furniture. The intermediate scale furnace was a premixed, natural gas fed, forced air furnace. A maximum furnace temperature of nominally $1100{ }^{\circ} \mathrm{C}$ for approximately 15 minutes was selected to provide an exposure that could potentially melt brass receptacle components. Thirty-six receptacles were installed in each wall assembly used in the compartment fires and furnace fire testing. The wall assemblies were constructed of 2 by 4 inch dimensional lumber with the majority of receptacles enclosed with lumber on four sides. The wall assemblies were enclosed on the front and back surfaces with $12.7 \mathrm{~mm}(0.5 \mathrm{in})$ thick gypsum wall board effectively isolating each receptacle in its own wall cavity. No insulation was used within the wall cavity. More details regarding the fire testing and laboratory testing can be found in the full report [15].

\section{Experimental Variables}

Table 1 presents an overview of the variables evaluated in laboratory testing and fire exposure testing. This research was aimed at conducting tests with components that were representative of equipment typically found in residences within the U.S. New receptacles were selected based on the primary plastic materials in use today; both a PVC receptacle and a polypropylene receptacle were used. In addition, some aged receptacles, constructed of thermosets (e.g. phenolics and urea formaldehyde), were used. The specific type of thermoset used for each receptacle was not determined due to the large number of different thermoset receptacles used. Aged receptacles were between 20 and 70 years old. For the $1 / 4$ turn loose configuration (see Table 1), screw terminals were tightened to a torque of $0.565 \mathrm{~N}-\mathrm{m}(5 \mathrm{in}-\mathrm{lb})$ and then rotated a $1 / 4$ turn (i.e., $90^{\circ}$ ) in the counter-clockwise direction as a consistent means to produce a terminal connection substantially looser than $0.113 \mathrm{~N}-\mathrm{m}(1 \mathrm{in}-\mathrm{lb})$, which was not achievable with the torque driver. Screw terminals were tightened using a CDI model 151SP adjustable cam-over type torque screw driver. The cam-over type torque screw driver was set using a calibrated Cedar model DID-4 digital torque screw driver (3.95 N-m [35 in-lb] max; +/- 0.5\% F.S.). All terminals on a receptacle had the same configuration (i.e., torque or removal/re-insertion cycles).

\section{EXPERIMENTAL RESULTS AND DISCUSSION}

Due to the numerous variables and receptacles tested in this work, it is not possible to present all of the data and analysis in this paper. For a complete description and analysis of the test data collected, refer to the full report [15]. 
Table 1. Simplified overview of test variables.

\begin{tabular}{|c|c|c|}
\hline Variable & Laboratory Overheat Testing & Fire Exposure Testing \\
\hline Wiring Method & $\begin{array}{l}\text { Back Wire Push-in } \\
\text { Side Wired (Screw) }\end{array}$ & Side Wired (Screw) \\
\hline Screw Terminal Torque & $\begin{array}{c}1 / 4 \text { Turn Loose }(<<0.11 \mathrm{~N}-\mathrm{m}) \\
0.11,0.34,0.56,1.7 \mathrm{~N}-\mathrm{m} \\
(1,3,5,15 \mathrm{in}-\mathrm{lb})\end{array}$ & $\begin{array}{c}1 / 4 \text { Turn Loose }(<<0.11 \mathrm{~N}-\mathrm{m}) \\
0.11,0.34,0.79,1.3 \mathrm{~N}-\mathrm{m} \\
(1,3,7,12 \mathrm{in}-\mathrm{lb})\end{array}$ \\
\hline $\begin{array}{c}\text { \# of Back Wire Removal } \\
\text { and Insertions }\end{array}$ & $0,1,2$ cycles & $\mathrm{N} / \mathrm{A}$ \\
\hline Receptacle Material & $\begin{array}{c}\text { PVC } \\
\text { Polypropylene } \\
\text { Thermosets } \\
\end{array}$ & $\begin{array}{c}\text { PVC } \\
\text { Polypropylene } \\
\text { Thermosets } \\
\end{array}$ \\
\hline Outlet Box Material & $\begin{array}{l}\text { None } \\
\text { PVC }\end{array}$ & $\begin{array}{c}\text { PVC } \\
\text { Galvanized Steel } \\
\end{array}$ \\
\hline $\begin{array}{r}\text { Faceplate } \\
\text { Material } \\
\end{array}$ & $\begin{array}{l}\text { None } \\
\text { Nylon }\end{array}$ & $\begin{array}{l}\text { Painted Steel } \\
\text { Nylon }\end{array}$ \\
\hline Use Conditions & $\begin{array}{c}\text { Vibration } \\
\text { Cyclic Loading } \\
\end{array}$ & $\mathrm{N} / \mathrm{A}$ \\
\hline Electrical State & Energized & $\begin{array}{c}\text { Non-Energized } \\
\text { Energized } \\
\text { Energized w/ Load } \\
\end{array}$ \\
\hline
\end{tabular}

\section{Potential for Overheating Connections}

In this work, overheating of receptacles was determined by visual indicators. These visual indicators included: discoloration of metal conductors; discoloration of plastic materials (wiring insulation, receptacle body); deposits of oxidation or corrosion products on metal conductors; charring or melting of plastic materials; glowing connections; loss of plating on receptacle screws; and dezincification of brass components. None of the receptacles with screw terminal connections having torques of $0.339 \mathrm{~N}-\mathrm{m}$ (51 receptacles), $0.565 \mathrm{~N}-\mathrm{m}(10), 0.791 \mathrm{~N}-\mathrm{m}(10)$, and $1.69 \mathrm{~N}-\mathrm{m}$ (8) experienced any visual indicators of overheating throughout the test periods. The majority of receptacles having torques of $1 \mathrm{in}-1 \mathrm{~b}$ or the $1 / 4$ turn loose configuration $(<<0.113 \mathrm{~N}-\mathrm{m})$, however, did exhibit signs of overheating at one or more of the screw terminals. This is generally consistent with other work in the literature [3, 4]. Most (252) of the receptacles were tested at a current of $15 \mathrm{~A}$. The remaining 78 receptacles were tested at currents of $3 \mathrm{~A}$ for 90 days, followed by 6A for 114 days, and then 9A for 192 days. Only one receptacle showed signs of oxide formation at a current of $6 \mathrm{~A}$. After the current was increased to 9A, approximately half of the receptacles having torques of $0.113 \mathrm{~N}-\mathrm{m}$ and the $1 / 4$ turn loose configuration began to exhibit signs of overheating. Only three of the 42 back-wired push-in connected receptacles (at 15A) showed indicators of overheating. All of these receptacles were subjected to daily vibrations and were installed with one prior removal and reinsertion cycle for each wire.

\section{Mechanisms and Effects of Overheating}

It is well accepted that oxidation of copper conductors at a loose connection can lead to overheating and potentially glowing at the connection. This oxidation is typically dark grey or black in color. Dark oxidation was observed to have formed on a large portion of receptacles in conjunction with the development of the overheating connections. Discoloration, charring, and melting of the receptacle materials also occurred as a result of overheating. It was quite common for receptacles to show multiple signs of overheating at multiple terminals. Figure 1 shows a PVC receptacle exhibiting multiple signatures of overheating, including oxidation (likely $\mathrm{CuO}$ ), discoloration of the PVC body, discoloration of wiring, and loss of nickel plating on the terminal screws. Discoloration of this sort was common for the PVC receptacles and spread radially outward from the overheating screw connections and along the wiring. 
Polypropylene receptacles tended to melt near the overheating connection rather than discolor, and the thermoset receptacles would crack and discolor near the overheated connection.

For cases where glowing was developed at the screw terminal, it took one of two forms. Either a reddishorange glow of the entire screw terminal and conductor developed, or a bright glow spot at some point along the conductor at the screw terminal developed. In some cases, the glowing transitioned from a localized spot to an overall glow at the terminal or viceversa. Temperature measurements were taken for some glowing connections using a handheld thermocouple reader and a $1.6 \mathrm{~mm}$ (0.0625 inch) diameter Type-K thermocouple. Temperatures of up to $600^{\circ} \mathrm{C}$ and $1100^{\circ} \mathrm{C}$ were measured at overall glow and localized glow spots, respectively. Some measured temperatures were higher than the melting point of copper $\left(1085^{\circ} \mathrm{C}\right)$ and brass $\left(930^{\circ} \mathrm{C}\right)$. Despite local temperatures above the melting point of

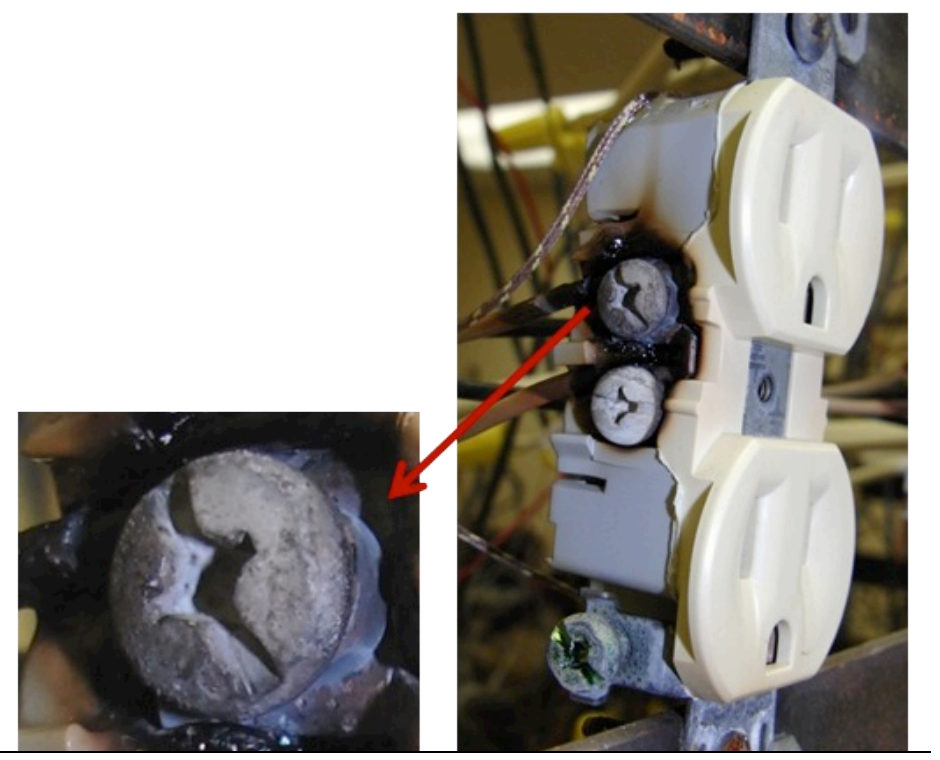

Fig. 1. Oxidation, discoloration, loss of plating on screw from an overheated PVC receptacle. brass, none of the receptacles where glowing was observed had the brass receptacle contacts show signs of melting. It is expected that the size and arrangement of the brass contacts allowed the heat from the glowing conductor to dissipate and the brass to remain below its melting temperature.

Development of glowing was quite fickle and usually began without any apparent stimulus. In some cases, glowing would start after several small arcs occurred when power was cycled for the receptacles. In other cases, glowing would appear seemingly at a random time when the receptacle was energized. Glowing could last for days, would disappear if power was removed, and often reappeared within an hour or more after power was re-applied to the circuit. In addition, glowing sometimes stopped and re-started days later for no apparent reason. When the localized glow spots remained for extended periods (i.e., hours), the glow spot would migrate in a counterclockwise direction around the screw head as shown in Figure 2 . As the glow spot moved, the copper conductor would melt at the spot location and re-solidify (i.e., weld). In some cases, this motion created curved striations in the welded conductor. Two examples of curved striations on welded conductors are shown in Figure 3. These striations were similar in appearance to the layers of the "nuggets" produced by Korinek et al [7]. The curved striations in the welded conductor are a clear indication that a glowing connection was present. Approximately $80 \%$ of receptacles having welded conductors (41) had only one welded conductor. In ten receptacles, two welded conductors were observed on the same receptacle; the two welded conductors were always on the same side of the receptacle (i.e., neutral or hot side) and shared a common brass contact. A total of 61 welded conductors were observed; 37 had curved striations.

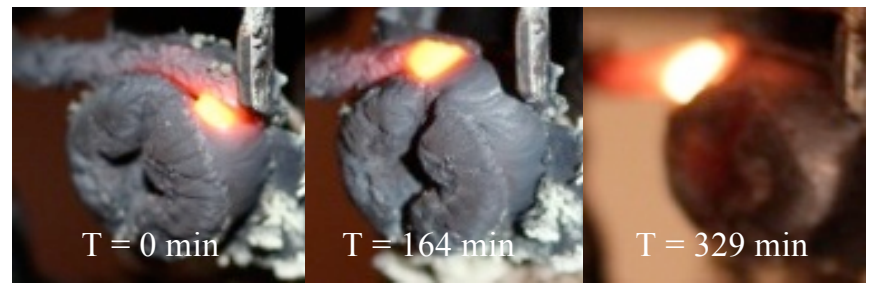

Fig. 2. Movement of glow spot on receptacle connection at various times, $\mathrm{T}$.
Once the glow spot had moved to the part of the conductor not underneath the screw head, the conductor would begin to neck. As a result of the necking, the conductors typically severed, sometimes accompanied by a parting arc. The severing of the conductor at the glow spot produced various characteristic ends on the conductors such as those shown in Figure 4. Some severed ends had round and sometimes dimpled globules, others had flat ends with no globule, and others had irregular shaped 
necked or split ends. Further examination of the round conductor ends revealed that they were comprised of a flat head beneath a rounded cap of solidified copper oxide.

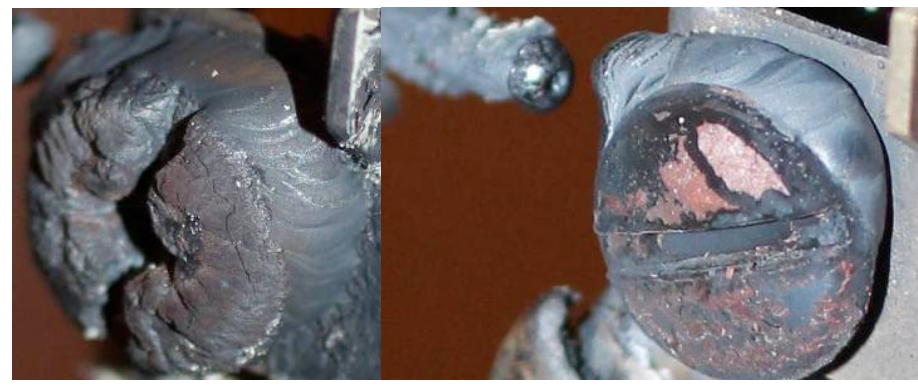

Fig. 3. Curved striations on two welded conductors.

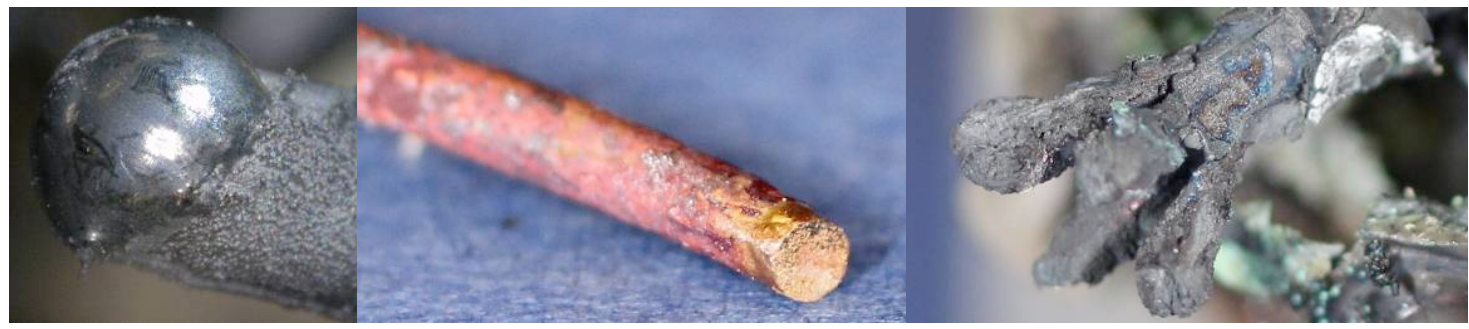

Figure 4: Various severed conductor ends from glowing connections.

Copper and copper alloys are resistant to corrosion by dry gasses at ambient temperatures or lower [16]. However, copper alloys are more vulnerable to corrosion from liquid/vapor chlorine environments and at elevated temperatures. Figure 5 shows a receptacle that has a white colored deposit on the surface of the wires. The deposits were generally present along the length of the exposed section of wire and were distinct layers atop the copper wire that stopped at the boundary between the exposed wire and the intact wire insulation. The white colored deposits were only observed on the PVC receptacles, while copper oxide deposits were found on PVC, polypropylene, and thermoset receptacles. Scanning Electron Microscopy with Energy-dispersive X-ray Spectroscopy (SEM/EDS) analysis of the white deposit revealed that it was primarily chlorine solids. The chlorine deposits were a result of vapors released from the thermally degraded PVC receptacle bodies. When PVC is heated, hydrogen chloride $(\mathrm{HCl})$ gas is generated; $\mathrm{HCl}$ combines with atmospheric moisture to form hydrochloric acid. Copper has a fair resistance to corrosion by hydrochloric acid [16]. White corrosion products were also found on the brass contacts where dezincification was present. Although the resistance of the corrosion products were not measured, it is likely that they increased the electrical resistance at the connections, much like the copper oxides do.

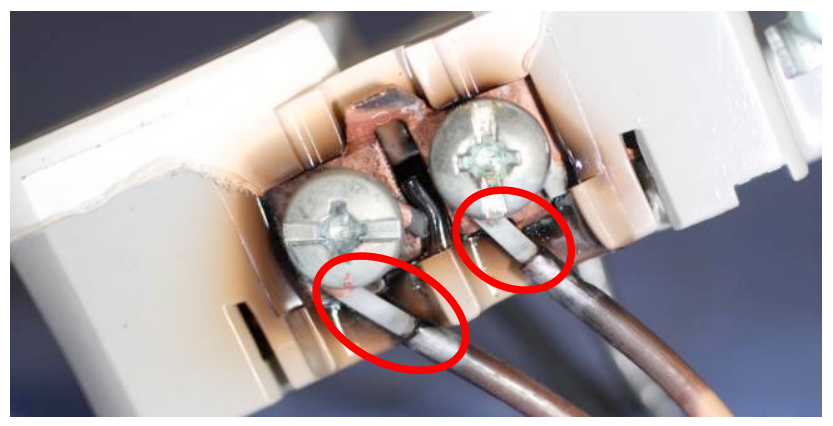

Fig. 5. Photograph showing white chlorine deposits on the wires of a PVC receptacle.

Another visual indicator of overheating and corrosion in receptacles is the change in appearance of the brass receptacle contacts from yellow to a coppery color. This is an indication that the zinc from the brass has been selectively leeched from the surface due to the corrosion [17]. Selective leeching of zinc from brass due to corrosion is referred to as dezincification. The hydrogen chloride vapors produced by the heated PVC provided the corrosive atmosphere. The overall dimensions of the dezincified brass contacts did not appear to change. However, the copper that remains after dezincification is porous and mechanically weak [17]. It is unclear to what effect dezincification has on the electrical conductivity of the brass contacts. A receptacle's brass receptacle contacts which experienced dezincification were sectioned and polished. A microscopic image (500x) of the cross-sectioned brass contact, shown in Figure 6, reveals dezincification occurring on the 
surface of the contact. There is a visible line of demarcation between the bulk brass (yellow) and the dezincified brass (copper colored). The dezincified brass is a relatively porous layer approximately 5 microns ( $1.9 \times 10^{-4}$ inches $)$ in thickness compared to the $0.76 \mathrm{~mm}(0.03$ inch) thick brass contact.

In twenty-eight cases, a heavy layer of corrosion developed on the screw terminals of receptacles with failure events. This was termed an enlarged screw head and was a clear indication that a glowing connection and chlorine corrosion were present. In one receptacle, three enlarged screw heads were found. Of the 28 enlarged screw heads observed, 22 had welded conductors and only 4 had curved striations present. For the enlarged screw heads, rather than a dark oxidation of the copper conductor causing the overheating at the terminal, the layer of white corrosion previously described was deposited on the conductor. This layer eventually developed into a crystalline deposit which corroded the screw; this progression

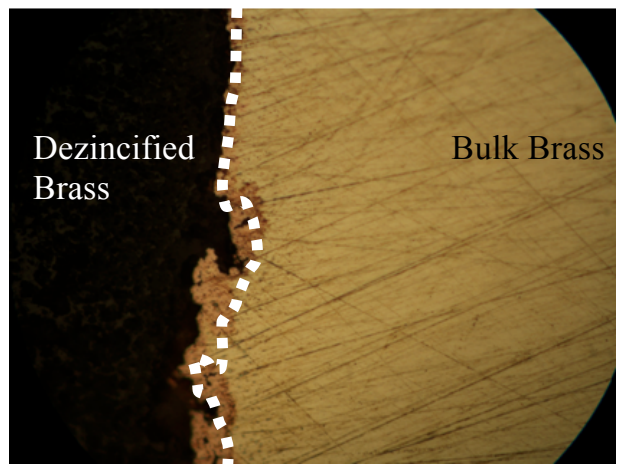

Fig. 6. Image (500x) of a polished and sectioned brass contact showing dezincification. is shown for a receptacle in Figure 7. This specific series of events was observed in a limited number of cases, but due to the number of receptacles tested it was not possible to determine whether this development occurred for each of the other cases where an enlarged screw head was found. The enlarged screw heads had a black, grey, or reddish color, and fine surface porosity though the surface was relatively smooth; in general, the screw slots remained visible.

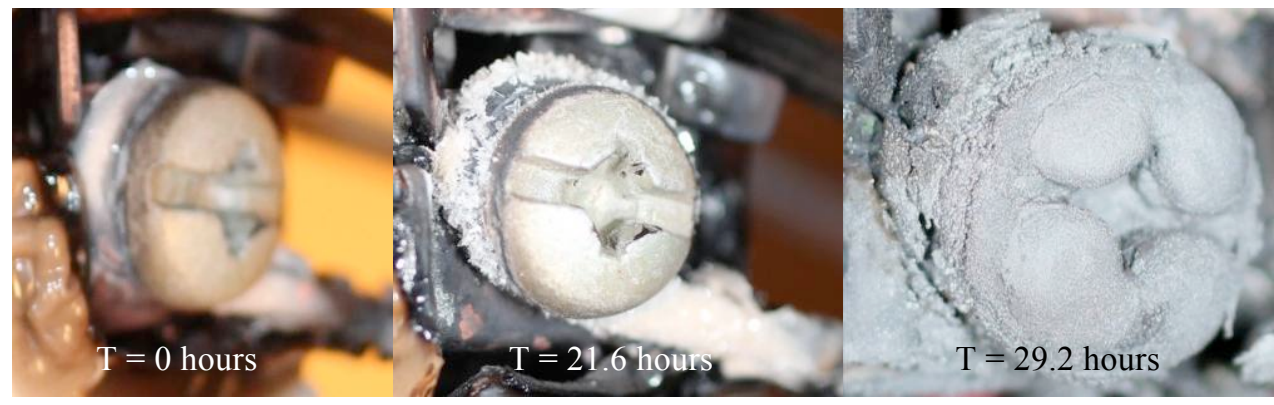

Fig. 7. Development of an enlarged screw head on a PVC receptacle at various times, T.

\section{Receptacle Failure Events}

Out of the 408 receptacle trials, 85 had overheating events leading to failure of the receptacle. A failure event was defined as an overheating connection accompanied by the evolution of smoke, flames, electrical arcing, and/or a glowing connection resulting in an electrical failure of the receptacle. These events were allowed to progress without interference from test personnel. Often, the events occurred at times of the day when no event personnel were present. Examination of surveillance video footage of the failure events revealed their progression. After the events, the receptacles were removed from the test circuit and forensically documented. The various overheating events included:

- Conductor severed with accompanying arc

- Conductor severed without accompanying arc

- Conductor severed; arc unknown

- Shorted - hot to ground

- Shorted - neutral to ground

- $\quad$ Shorted - hot to neutral

- Flaming ignition

- Series arcing at screw terminal 
There was some overlap in the failure events. For instance, some, such as flaming ignition, also had a shorting event or a severed conductor. In cases where multiple failure events were present, the precedence in terms of classification for analysis purposes was as follows: flaming ignition $>$ severed conductors $>$ shorting. Each receptacle failure was classified as a single event. The time to an event was calculated as the number of days between when the receptacles were initially energized until the day when they were removed from the test rack due to the failure. The times to failure covered a large range, from 5 days to 365 days with an average time to failure of 161 days. There were no obvious trends in the data which suggested that any one failure event was more likely to occur quicker or slower than another. The large range of times to failures provides two significant insights. First, the quickest time to failure (5 days) is a rather short span of time in the expected life of a receptacle, which is on the order of a few decades. This implies that a specific receptacle failure could be tied to a recent event with respect to the time of failure (i.e., receptacle modification, installation, load addition, etc.). On the other hand, the longest time to failure of 365 days is noteworthy in that it suggests that failure events can be quite removed from the initial installation or modification, especially considering that receptacles may not have current flow for duty cycles as high as those tested in this research (powered 23 hours/day).

Flaming ignition of receptacles occurred in twelve instances, or approximately $14 \%$ of the receptacle failure events. These events are the most significant in that they demonstrate the ability of overheating receptacles to develop into potentially competent ignition sources. Flaming ignition occurred for receptacles constructed of polypropylene and PVC. Both receptacles installed in outlet boxes with faceplates and those in the open air had flaming ignition failures. Flaming ignition did not occur for thermoset receptacles; however, these were not tested with outlet boxes and faceplates, but only as open devices. Although the loosest connections (i.e., $1 / 4$ turn loose $[<<0.113 \mathrm{~N}-\mathrm{m}]$ ) comprised the majority of flaming ignition events (10 out of 12), other factors, such as material properties and configuration (i.e., outlet box, faceplate, etc.), may have influenced the development of a heated connection to a flaming event more than the difference between torque conditions. Developing an overheated connection is dependent on the looseness of the connection; however, once it is established, the transition to flaming is likely governed by other variables.

The flaming ignition events were very diverse in terms of the duration, size, and location of the flames. The duration of flaming events ranged from as little as 8 seconds to as long as 4 minutes. In all cases, the receptacles self-extinguished and the fires did not ignite adjacent receptacles (located $7.5 \mathrm{~cm}(3.0 \mathrm{in}$.) above and to the side). Maximum flame heights ranged from $7.6 \mathrm{~cm}(3.0 \mathrm{in}$.) to $46 \mathrm{~cm}$ (18 in.). Often, for the larger flame heights (i.e., greater than or equal to $25.4 \mathrm{~cm}$ [10 in.]), the flames were largest during the first $10 \%$ or so of the total event duration, and diminished quite drastically for the rest of the event. In the case of the smaller flaming events, flame heights were more consistent throughout the duration of the event. Only one of the twelve flaming events tripped the circuit breaker.

\section{Fire Damage to Receptacles - Prior Overheating Evidence}

Twenty-one of the receptacles having had overheating failure events and one receptacle with a partially welded conductor were placed in a furnace exposure test and subjected to temperatures up to $1100{ }^{\circ} \mathrm{C}$ for 15 minutes. In general, the physical evidence of overheated connections (e.g., welded conductors, enlarged screw heads, severed conductors) did persist even after the flashover type fire exposure. The primary visual changes observed were to the color; in some cases curved striations on welded conductors were not present after the exposure. Due to the high temperature exposure, the receptacle bodies were mostly or totally consumed; therefore, the localized damage to the receptacle body materials from overheating was not present.

Of the 21 furnace test samples, twelve receptacles had a total of thirteen combined welded conductors. Of these thirteen welded conductors, 11 had curved striations visible prior to fire exposure. After the fire exposure, all of the welded conductors remained identifiable. However, the curved striations could only be identified on 9 out of the 11. In general, the curved striations became more difficult to see after the furnace exposure. Figure 9 shows a welded conductor with curved striations before and after fire exposure. 


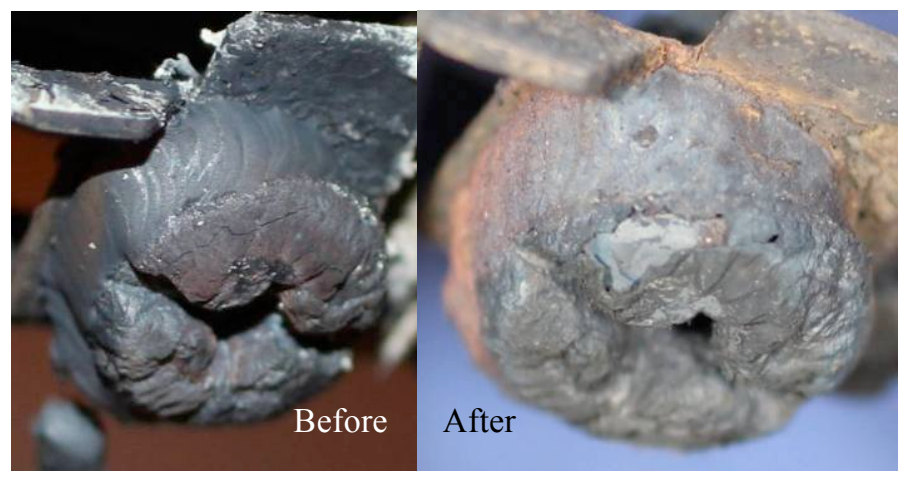

Fig. 9. Welded conductor with curved striations before and after fire exposure.

changes to an enlarged screw head before and after the exposure.
Five receptacles with enlarged screw heads were placed in the furnace fire test. After the fire exposure, 4 out of 5 of the enlarged screw heads remained identifiable. In general, the shape of the enlarged screw heads remained, but the color changed. The one case where the enlarged screw head was not identifiable after the furnace exposure only had a partial surface buildup prior. After the furnace fire exposure, the buildup on the enlarged screw head was not distinctly different from the screw head that was not enlarged prior to testing. Figure 10 shows the

Fourteen receptacles that had severed conductors were placed in the furnace fire test. The severed wire ends from five of the receptacles were not included in this test. Of the 9 wire ends from severed conductors that were exposed to the furnace, all 9 persisted after the exposure. Much like the welded conductors with curved striations, the only change in the appearance of the severed conductor ends was a color change. The general shape of the severed conductors did not change due to the furnace exposure. Thirteen of the fourteen screw sides of the severed conductor ends persisted after the fire exposure. The only screw side of the severed conductor that did not persist after the furnace exposure showed some signs of melting of the copper conductor at the location where the conductor severed. The shapes, including dimples at the center of the severed conductors, did not change due to the furnace exposure. Much like the welded conductors with curved striations, the only change in the appearance of severed conductor ends was a color change. The general shape of the severed conductors did not change due to the furnace exposure.

After the furnace exposure to receptacles with prior overheating, a number of $\mathrm{PVC}$ receptacles were observed to have internal contacts that were severely thinned by oxidation and overheating. Due to the plastic that had remained on the receptacles after the failure events, these contacts could not be seen in their entirety prior to the furnace exposure. An example of the thinned portion of the contacts is shown in Figure 11 (see arrow). The thinning of the contacts occurred in the vicinity of the screw connection that was overheating and was relatively uniform over the contacts. This
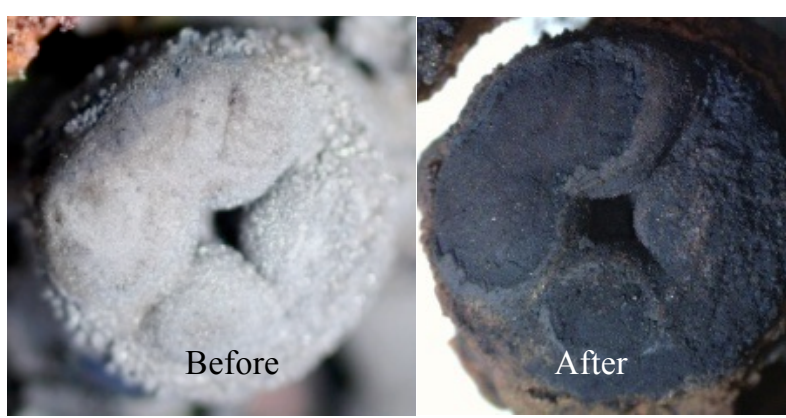

Fig. 10. Enlarged screw head before and after furnace exposure. thinning was not in the vicinity of the locations where arcing was observed to occur. In general, the thickness of the contacts was reduced to about half of the original thickness. Since the thinned contacts could only be viewed after the furnace exposure, it is unclear whether or not they had changed due to the furnace exposure.

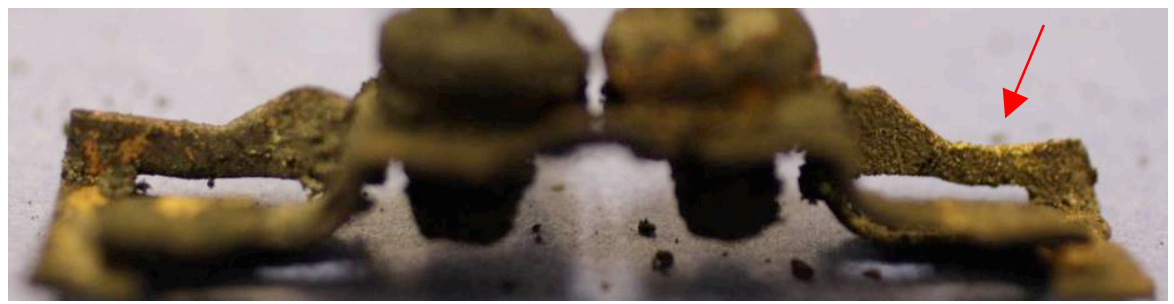

Fig. 11. Photograph showing thinning of brass receptacle contacts. 


\section{Distinguishing Between Arcing and Melting Damage}

Distinguishing between arcing and thermal melting damage was based on the presence of visual indicators of arcing. The following characteristics are listed in the proposed changes to NFPA 921 (2014) as "frequently exhibited [in] arc damaged conductors:" [14]

- Localized point of contact

- Sharp demarcation between damaged and undamaged area

- Copper drawing lines visible outside of damaged area

- Corresponding damage on the opposing conductor

- Resolidification waves

- Locally enlarged grain size

- High internal porosity when viewed in a cross-section

- Localized round depressions

- $\quad$ Small beads \& divots over a limited area

- Round, smooth shape of artifact

The presence of tooling marks, such as defined edges and stamped lettering outside of the damaged area, for arcing in brass and steel receptacle components was used as an analogous characteristic to the presence of copper drawing lines for copper wiring. A portion of the receptacles from this test program was evaluated for the presence of the aforementioned characteristic traits of arcing damage. The purpose of this exercise was to assess which characteristic traits were effective in assessing potential arcing damage on receptacle components and wiring. All of the 39 receptacles which failed during testing and also had arcing damage were evaluated; this included 95 individual conductors. Forty-seven receptacles with fire induced arcing were evaluated; this included 87 individual conductors. All of the evaluated receptacles with fireinduced arcing were energized or energized with a load. Thirty-seven receptacles with fire induced melting were evaluated; this included 57 individual conductors. All of the receptacles evaluated for melting were non-energized receptacles.

Each receptacle was evaluated for the aforementioned characteristics of arcing with the exception of the grain structure (i.e., locally enlarged grain size). This characteristic was omitted because it was not able to be evaluated visually. Where multiple conductors exhibited damage, each conductor was evaluated independently. For each characteristic, there were three possible outcomes: Yes, No, and Possible. Possible indicated that confirmation could not be made either for or against the presence of the characteristic. All of the evaluations were conducted by the same person. Every effort was made to evaluate the conductors in a consistent manner; however, there is some subjectivity present in the evaluations due to the qualitative nature of the characteristic traits. Table 2 provides an overview of the characteristic traits of arcing that were evaluated as well as a photograph exhibiting each trait. The photographs presented in Table 2 are prime examples of the characteristic traits; however, some traits had a spectrum of possible variations.

Corresponding damage on the opposing conductor is a characteristic of arcing that should be present in every instance of arcing. This is because arcing, at a minimum, requires two conductors, whether they are two parts of the same conductor in series or two separate conductors in parallel. However, dirt, debris, physical damage, thermal damage, or corrosion can destroy or obscure the damage on a conductor. In this study, a large portion of conductors with damage from arcing $(93 \%)$ had a positive identification of corresponding damage on the opposing conductor. On the other hand, only four (7\%) of the conductors with fire melting had corresponding damage on the opposing conductor. These four conductors (two pairs of stranded copper wires) were fused together from the fire exposure. These results indicate that corresponding damage on multiple conductors is a reliable indicator of arcing and rare for melting damage.

Because individual arcs are typically small in size $(<1 \mathrm{~cm})$, short in duration $(<<1$ second), and high in temperature $\left(>5000{ }^{\circ} \mathrm{C}\right)$, damage to the conductors tends to be localized with a sharp line of demarcation between damaged and undamaged areas. Where multiple arcs occur in the same location, the damage area can grow in size and thus become non-localized. The authors did not define a cutoff for the size of the damage area for determining whether damage was localized. A large portion of conductors with arcing damage (95\%) had a positive identification of localized damage with a sharp line of demarcation. Those few conductors without localized damage with a sharp line of demarcation were brass and steel only. Only $12 \%$ of conductors with melting had localized damage with a sharp line of demarcation; all of these instances were observed on solid copper receptacle wiring. The distinct line of demarcation of wire damage 
can be explained by the directional fire exposure (i.e., from front to back of the receptacle) with the wires located behind the receptacle in the box. Overall, the data clearly shows a strong correlation for a sharp line of demarcation with arcing damage and a weak correlation for melting.

The round, smooth shape often exhibited by arcing damage on wiring has led to the use of the generic term of arc bead for describing arcing damage. While the proposed changes to NFPA 921 [14] include the round smooth shape as a characteristic trait of arcing, Section 8.11.1.2 of NFPA 921 [13] states that arcing damage can be "notches in the sides of the conductors, or rounded or irregular-shaped beading on the end of a severed conductor." This information provided by NFPA 921, while accurate, is not clear guidance on differentiating between arcing and melting in that it essentially states that both regular (i.e., round and smooth) as well as irregular arc damage can be observed. Only $40 \%$ of the conductors with arcing damage were round and smooth in shape, whereas $12 \%$ of melted conductors had a round and smooth shape. While a notable number of arcing conductors had this trait, the lack of a large difference in proportions of arcing and melting damage which are round and smooth in shape suggests that this trait is not a strong differentiating indicator between arcing and melting.

Resolidification waves in arcing damage arise from the rapid cooling associated with arcing events. This trait appears as concentric rings (i.e., waves or ripples) emanating from the center of the arc location. Only a small portion $(12 \%)$ of conductors with arcing damage exhibited resolidification waves. No conductors with melting damage were observed with any damage resembling resolidification waves. Resolidification waves were observed on steel, brass, and copper conductors, but were most often located on the steel receptacle components. Despite the low percentages of arc damaged conductors with resolidification waves present, this characteristic trait is a strong indicator that arcing occurred. The resolidification waves themselves are unique compared to the visual appearance of melting. The regular, concentric rings are not able to be produced by fire melting due to the relatively slow process of fire-melting and cooling compared to arcing.

Tooling marks come from the manufacturing process of metal components of receptacles and wiring. These processes mark the surface with a regular pattern or form a distinct shape. Tooling marks include defined edges and lettering for stamped and bent brass and steel receptacle components and copper drawing lines for copper wires. When exposed to temperatures on the order of the melting temperature of the conductor, these tooling marks can begin to be destroyed. A large portion of conductors with arcing damage (80\%) had a positive identification of tooling marks outside the area of damage. Only one conductor (1.7\%) with melting damage had tooling marks visible outside a localized damage area; this was a solid copper wire. This characteristic trait of arcing is a parallel method of confirming that damage to the conductor is localized and has a sharp line of demarcation, but is less likely to be present if exposure temperatures were close to the melting temperature of the subject material.

In general, the evaluations of arcing and melting damage were external evaluations of the conductors; the internal structure of the arcing and melting damage was not systematically evaluated. However, some of the arcing locations examined had two conductors fused together by arcing. During the examination, the conductors were pulled apart to reveal the internal structure of the connecting arc bead. In 21 conductors, large voids were observed inside the arc bead. In 8 conductors, porosity was visually evident on the surface of the conductor, but the amount of internal porosity and size of the voids was not evident. These conductors were classified as having possible high internal porosity. Internal porosity was not examined for all of the conductors with arcing or melting damage. Because there has not been any rigorous study in the literature which quantifies the size and percent by volume of voids in arc beads, the value of this characteristic trait in an arc damage determination is limited.

Spatter, or sprayed molten material, is often ejected outward in all directions from the arc location when arcing occurs. This material is then deposited on surfaces further away from the arcing location. Spatter consists of very small spherical particles of the metal(s) which were involved in arcing. Since the particles cool very quickly, they retain their spherical shape when they impact a surface. These spheres are typically on the order of $0.1 \mathrm{~mm}$ or less, but some can be larger. While fire melting can produce molten metal that fall (in the direction of gravity) onto surfaces, these do not tend to cool rapidly and can deform when striking the surface. Therefore, the very small spherical spatter particles from arcing are generally unique compared to the deposits produced by melting. 
Table 2. Overview of characteristic traits of damage from arcing.

\begin{tabular}{|c|c|c|}
\hline $\begin{array}{c}\text { Characteristic } \\
\text { Trait }\end{array}$ & Additional Details & Example Photograph from Arcing Damage \\
\hline $\begin{array}{l}\text { Corresponding } \\
\text { Damage on the } \\
\text { Opposing } \\
\text { Conductor }\end{array}$ & $\begin{array}{l}\text { Damage located on } \\
\text { another conductor } \\
\text { proximate to the area of } \\
\text { interest and in a location } \\
\text { where arcing was } \\
\text { possible. } \\
\end{array}$ & 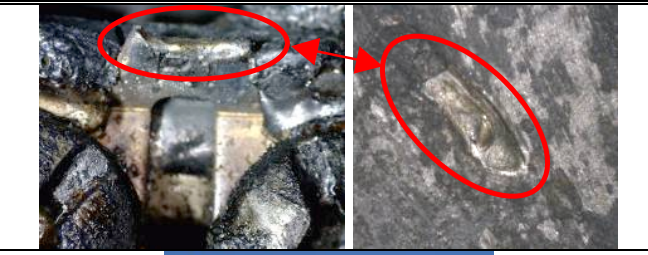 \\
\hline $\begin{array}{l}\text { Localized Point } \\
\text { of Contact with } \\
\text { Sharp Line of } \\
\text { Demarcation }\end{array}$ & N/A & \\
\hline $\begin{array}{l}\text { Round, Smooth } \\
\text { Shape }\end{array}$ & $\begin{array}{c}\text { Some or all of the damage } \\
\text { is rounded without jagged } \\
\text { or rough surfaces and } \\
\text { edges. }\end{array}$ & \\
\hline $\begin{array}{c}\text { Resolidification } \\
\text { Waves }\end{array}$ & $\begin{array}{c}\text { Concentric rings } \\
\text { emanating from the center } \\
\text { of the arcing damage. }\end{array}$ & \\
\hline $\begin{array}{l}\text { Tooling Marks } \\
\text { Visible Outside } \\
\text { Damage Area }\end{array}$ & $\begin{array}{l}\text { Stamped lettering, copper } \\
\text { drawing lines, crisp edges } \\
\text { of receptacle components } \\
\text { remain outside of the } \\
\text { arcing location. }\end{array}$ & \\
\hline $\begin{array}{l}\text { High Internal } \\
\text { Porosity }\end{array}$ & $\begin{array}{c}\text { Large percentage of voids } \\
\text { internal to the arc } \\
\text { damage. }\end{array}$ & \\
\hline Spatter Deposits & $\begin{array}{l}\text { Small spherical globules } \\
\text { ejected during arcing; can } \\
\text { be located on surfaces } \\
\text { away from the arcing } \\
\text { location. }\end{array}$ & \\
\hline
\end{tabular}

A small fraction (16\%) of receptacles with arcing produced spatter that was identified, while only one instance $(1.7 \%)$ of melting had evidence that could be visually identified as spatter. The melted conductor identified with spatter had a single spherical particle on the end of the conductor; the spherical particle was on the larger side of what could be considered spatter. Despite the low percentages of arc damaged conductors with spatter present, this characteristic trait is a strong indicator that arcing occurred. The small 
spherical particles are not readily produced by melting and can be deposited in all directions, while melting particles can only fall in the direction of gravity.

\section{CONCLUSIONS}

This study addresses the impact of a wide range of variables on the formation of overheating receptacle connections. The primary variables studied were the looseness of the connection, receptacle materials, electrical load, and surrounding materials (i.e., installation in an outlet box with faceplate); only copper wiring was used. A number of visual indicators of overheating receptacle connections were observed. These included discoloration, melting, dripping, cracking, charring, oxidation, corrosion, and dezincification. Based on this testing, both a very loose connection and a relatively high current load are required for overheating to begin at a receptacle screw connection $(<0.339 \mathrm{~N}-\mathrm{m}$ and $\geq 9$ A). Despite some negative reputations in the past, the current back wired push-in connections evaluated were robust and not prone to overheating. Not only were loose connections and relatively high currents required to develop overheating of back wired push-in connections, but mechanical vibration of the receptacle was as well.

Two primary mechanisms leading to overheating of receptacle connections were observed; the formation of copper oxides at terminal connections and self-induced corrosion of terminals on PVC receptacles. All observations indicated that the oxide development in loose terminal connections followed that described in the literature. Glowing connections were formed on receptacle screw terminal connections. While the formation of glowing connections was limited to only the loosest screw connections (i.e., $0.113 \mathrm{~N}-\mathrm{m}$ and less), their development and appearance was rather inconsistent. Glowing appeared and disappeared at random time intervals and did not appear on every connection of $0.113 \mathrm{~N}-\mathrm{m}$ in-lb and less. Glowing receptacle connections produced distinct evidence including: welded copper conductors at screw terminals, severed conductors at or near the screw head, and enlarged screw heads due to corrosion. These types of evidence are unique compared to melting and arcing events from external fire exposure. Multiple receptacle connection failure modes were identified, including flaming ignition. Flaming ignition events $(\sim 14 \%$ of all failure events) were large enough both in flame size and duration to potentially ignite a range of proximate materials. The majority of flaming events $(83 \%)$ developed from very loose connections $(<<0.113 \mathrm{~N}-\mathrm{m})$. Developing an overheated connection is dependent on the looseness of the connection; however, once it is established, the transition to flaming is likely governed by other variables, such as material properties and configuration (i.e., outlet box, faceplate, etc.).

A number of receptacles with evidence of overheating, including welded conductors, enlarged screw heads, and severed conductors, were placed in an equivalent flashover exposure with temperatures upwards of $1100^{\circ} \mathrm{C}$ for 15 minutes. The majority of the evidence of glowing on these receptacles persisted after the fire exposure with only minor visual changes. The primary visual changes observed were to the color; in some cases curved striations on welded conductors were not present after the fire exposure.

The prevalence of characteristic traits of arcing noted in the literature was evaluated. A round smooth shape was found on a number of conductors with arcing damage, but most of the arcing damage was irregular shaped. Resolidification waves and spatter deposits, despite only being found in a small percentage of cases, were very strong indicators that arcing had occurred. This is because melting cannot produce these two distinct indicators. Corresponding damage on multiple conductors is also a very reliable indicator of arcing and is rare for melting damage. Sharp lines of demarcation of localized damage are strongly correlated to arcing (occurring for $95 \%$ of conductors with arc damage). Similarly, tooling marks can be used as a means to distinguish localized damage.

\section{ACKNOWLEDGEMENTS}

This project was supported by Award No. 2010-DN-BX-K218 awarded by the National Institute of Justice, Office of Justice Programs, U.S. Dept. of Justice. The opinions, findings, and conclusions or recommendations expressed in this publication are those of the authors and do not necessarily reflect those of the U.S. Dept. of Justice. The authors would also like to thank the assistance of the Travelers Engineering Lab and the ATF Fire Research Lab for providing invaluable support in analysis and testing. 


\section{REFERENCES}

[1] Hall, J.R., Home Electrical Fires, National Fire Protection Association, Quincy, MA, 2010.

[2] Askeland, D.R., The Science and Engineering of Materials, $2^{\text {nd }}$ Edition, Boston, MA, PWS-Kent Publishing Company, 1989.

[3] Meese, W. and Beausoliel, R., Exploratory Study of Glowing Electrical Connections, NBS Building Science Series, No. 103, National Bureau of Standards, Washington, DC, 1977.

[4] Ferrino-McAllister, J.L., Roby, R.J., and Milke, J.A., Heating at Electrical Contacts: Characterizing the Effects of Torque, Contact Area, and Movement on the Temperature of Residential Receptacles, Fire Technology, 42, pp. 49-74, 2006.

[5] Ettling, B., Glowing Connections, Fire Technology, 18 (4), pp. 344-349, 1982.

[6] Kim, D., Kim, H., Shong, K., Choi, C., The Properties of Oxidation Growth and Overheating by Poor Contact, $8^{\text {th }}$ International Conference on Properties and Applications of Dielectric Materials, pp. 392-395, 2006.

[7] Korinek, C.W., Korinek, T.C., Lopez, H.F., Pre and Post-Flashover Characteristics of An Electrically Overheated Poor Connection Between Copper and Steel, Fire and Materials, San Francisco, CA, 2013.

[8] Kuroyangi, T., Inoue, S., and Suzuki, H., Glowing Phenomena of Copper and Copper Materials and Their Electrical Characteristics, Copper Promotion Technical Research Group, 1981.

[9] Sletbak, J., Kristinsen, H., Sundklakk, Navik, G, Runde, M., Glowing Contact Areas in Loose Copper Wire Connections, IEEE Transactions on Components, Hybrids, and Manufacturing Technology, 15 (3), 1992.

[10] Twibell, J.D., Chapter 3 - Electricity and Fire, Fire Investigation, Daeid, N.N. (ed.), 2004.

[11] Babrauskas, V., Ignition Handbook, Fire Science Publishers, Issaquah, WA, 2003.

[12] Beland, B. and Saucier, D., Fire Damage to Aluminum Wired Receptacles, Fire Technology, 22 (4), 1986, http://dx.doi.org/10.1007/BF01038245

[13] NFPA, NFPA 921: Guide for Fire and Explosion Investigations, National Fire Protection Association, Quincy, MA, 2011.

[14] NFPA, 2013 Fall Revision Cycle - First Draft Report NFPA 921 Part 2 of 2, National Fire Protection Association, Quincy, MA, 2012.

[15] Benfer, M., Gottuk, D., Development and Analysis of Electrical Receptacle Fires, NIJ-2010-DNBX-K218, Baltimore, MD, 2013. $<$ http://www.haifire.com/Resources/publications/Development $\% 20$ and $\% 20$ Analysis $\% 20 \mathrm{of} \% 20 \mathrm{El}$ ectrical\%20Receptacle\%20Fires Benfer Gottuk 2013.pdf >

[16] ASM Materials Data Series, Handbook of Corrosion Data, $2^{\text {nd }}$ Edition, ASM, Materials Park, OH, Craig, B.D. and Anderson, D.S (ed.), 1995, pp. 19-21.

[17] Fontana, M.G., Corrosion Engineering, $3^{\text {rd }}$ Ed., McGraw-Hill, New York, NY, 1986. 